\title{
Effect of steroid use in anterior cervical discectomy and fusion: a randomized controlled trial
}

\author{
Shiveindra B. Jeyamohan, MD, Tyler J. Kenning, MD, Karen A. Petronis, NP, Paul J. Feustel, PhD, \\ Doniel Drazin, MD, and Darryl J. DiRisio, MD
}

Department of Neurosurgery, Albany Medical College, Albany, New York

\begin{abstract}
OBJECT Anterior cervical discectomy and fusion (ACDF) is an effective procedure for the treatment of cervical radiculopathy and/or myelopathy; however, postoperative dysphagia is a significant concern. Dexamethasone, although potentially protective against perioperative dysphagia and airway compromise, could inhibit fusion, a generally proinflammatory process. The authors conducted a prospective, randomized, double-blinded, controlled study of the effects of steroids on swallowing, the airway, and arthrodesis related to multilevel anterior cervical reconstruction in patients who were undergoing ACDF at Albany Medical Center between 2008 and 2012. The objective of this study was to determine if perioperative steroid use improves perioperative dysphagia and airway edema.

METHODS A total of 112 patients were enrolled and randomly assigned to receive saline or dexamethasone. Data gathered included demographics, functional status (including modified Japanese Orthopaedic Association myelopathy score, neck disability index, 12-Item Short-Form Health Survey score, and patient-reported visual analog scale score of axial and radiating pain), functional outcome swallowing scale score, interval postoperative imaging, fusion status, and complications/reoperations. Follow-up was performed at 1, 3, 6, 12, and 24 months, and CT was performed 6, 12, and 24 months after surgery for fusion assessment.
\end{abstract}

RESULTS Baseline demographics were not significantly different between the 2 groups, indicating adequate randomization. In terms of patient-reported functional and pain-related outcomes, there were no differences in the steroid and placebo groups. However, the severity of dysphagia in the postoperative period up to 1 month proved to be significantly lower in the steroid group than in the placebo group $(p=0.027)$. Furthermore, airway difficulty and a need for intubation trended toward significance in the placebo group $(p=0.057)$. Last, fusion rates at 6 months proved to be significantly lower in the steroid group but lost significance at 12 months ( $p=0.048$ and 0.57 , respectively).

CONCLUSIONS Dexamethasone administered perioperatively significantly improved swallowing function and airway edema and shortened length of stay. It did not affect pain, functional outcomes, or long-term swallowing status. However, it significantly delayed fusion, but the long-term fusion rates remained unaffected.

Clinical trial registration no.: NCT01065961 (clinicaltrials.gov)

http://thejns.org/doi/abs/10.3171/2014.12.SPINE14477

KEY WORDS cervical spine; dysphagia; fusion; steroid; dexamethasone

$\mathrm{A}$ NTERIOR cervical discectomy and fusion (ACDF) has become a widely accepted technique for addressing pathology in the cervical spine. Despite its associated morbidities, including dysphagia, airway compromise, vocal cord paresis/paralysis, and vascular injury, its benefits over posterior approaches are numerous. $5,8,17,25,31,32$

Perhaps the most common potential complication, dys- phagia is reported often, especially early in the postoperative course. Although it generally resolves in most patients, some continue to struggle with dysphagia for years postoperatively. It has been reported that more concerning, potentially life-threatening complications of airway compromise can occur in up to $6 \%$ of patients and that $2 \%$ require intubation. ${ }^{4,9,11,29}$ Believed to be related to the retraction of midline structures during surgery, edema has

ABBREVIATIONS ACDF = anterior cervical discectomy and fusion; FOSS = functional outcome swallowing scale; ODI = Oswestry Disability Index; SF-12 = 12 -ltem ShortForm Health Survey; VAS = visual analog scale.

SUBMITTED May 18, 2014. ACCEPTED December 3, 2014.

INCLUDE WHEN CITING Published online May 1, 2015; DOI: 10.3171/2014.12.SPINE14477.

DISCLOSURE Dr. DiRisio shares ownership in ReVivo. Drs. Drazin, Feustel, Petronis, Kenning, and Jeyamohan report no conflicts of interest concerning the materials or methods used in this study or the findings specified in this paper. 
been controlled with steroid administration. ${ }^{34}$ Recent evidence further suggests that local steroid placement during surgery also helps with swelling and odynophagia. ${ }^{20}$

Steroids given intraoperatively and postoperatively may lower the incidence of these adverse outcomes by reducing the degree of swelling within the anterior neck after local surgical tissue trauma. This effect is likely a result of the antiinflammatory properties of steroids, which serve to inhibit the release of inflammatory mediators and decrease capillary permeability. The use of steroids during spinal arthrodesis procedures, however, has historically been controversial because of a concern that antiinflammatory agents could reduce the rates of fusion, a proinflammatory process.

\section{Methods}

A prospective, randomized, double-blinded, controlled study in patients who underwent multilevel $(\geq 2$ motion segments) anterior cervical spine surgery between 2008 and 2012 was conducted. The study is registered with the ClinicalTrials.gov database (http://clinicaltrials.gov), and its registration no. is NCT01065961. One hundred twelve patients were enrolled with a target follow-up of 24 months. The Albany Medical Center Institutional Review Board approved the study. Our hypothesis stated that perioperative steroid administration would decrease dysphagia and airway complications without affecting long-term fusion rates. An a priori estimate was also calculated by using a presumed (from a previous study) dysphagia rate at 6 months of 19\%, with an expected reduction (based on our previous experience) to approximately $4 \%$ with steroid treatment. This calculation resulted in a power of $92 \%$ with a target of 200 patients. ${ }^{19}$

Patients who fulfilled the inclusion criteria (Table 1) were randomly assigned to receive intraoperative doses of either intravenous dexamethasone (Decadron; $0.2 \mathrm{mg} / \mathrm{kg}$ ) or an equivalent volume infusion of saline followed by 4 postoperative doses of $0.06 \mathrm{mg} / \mathrm{kg}$ of steroid or placebo, respectively, administered every 6 hours for the first 24 hours. The patients and the investigators were blinded to the treatment for the duration of the study. Postoperative steroid use was allowed for severe dysphagia and/or airway compromise that necessitated intubation; such deviations were recorded for consideration in the final analysis.

TABLE 1. Inclusion/exclusion criteria

\begin{tabular}{l}
\hline Inclusion criteria \\
\hline Age $\geq 18$ yrs \\
\hline $\begin{array}{c}\text { Cervical spondylosis requiring surgical treatment at } \geq 2 \text { motion } \\
\text { segments }\end{array}$ \\
\hline Ventrally approachable vertebral levels \\
\hline Exclusion criteria \\
\hline Age $<18$ yrs \\
\hline Pregnancy \\
\hline Chronic preop steroid use \\
\hline Coma or incapacitation, unable to provide consent \\
\hline Allergy to dexamethasone or related drugs \\
\hline
\end{tabular}

The data were reanalyzed after these cases were removed to evaluate the impact of postoperative steroid use on fusion rates.

The following preoperative parameters were collected for each patient: baseline demographics, smoking history, pain level and functional status (modified Japanese Orthopaedic Association myelopathy scores, neck disability index, 12-Item Short-Form Health Survey [SF-12] scores, and visual analog scale [VAS] scores), swallowing function (according to the functional outcome swallowing scale [FOSS]; Table 2), and the indication for surgery. In the immediate postoperative period, the percentage of patients who reported symptoms of dysphagia or airway compromise, the quantification of dysphagia symptoms on postoperative Day 1 according to the FOSS, and the length of inpatient stay were reviewed. At the 3-, 6-, 12-, and 24-month follow-up time points, the patients were assessed by using the FOSS and pain and functional scales (modified Japanese Orthopaedic Association myelopathy scores, neck disability index, VAS scores, and SF-12 scores). Fusion status was assessed by fine-cut cervical CT scans with reconstructions obtained at 6,12 , and 24 months. The spine was considered fused if bridging osseous trabeculae were seen spanning each operative level without any intervening radiographic lucencies (Fig. 1). All postoperative complications were also noted.

\section{Surgical Technique}

The senior author (D.J.D.) performed every multilevel anterior cervical spine surgery in this study by using the Smith-Robinson technique and a right-sided approach. The Thompson-Farley static (self-retaining) retractor was used in every case. Wide discectomies were performed with a combination of curettes and a high-speed drill, with the drill being used to remove the cartilaginous endplates of the vertebral bodies until bleeding bone was identified. The interbody device used was a carbon-fiber cage filled with hydroxyapatite, Type I collagen, and autologous iliac crest bone marrow aspirate. All anterior spinal osteophytes were removed with a drill to provide a flat surface for the DePuy (Johnson and Johnson) Swift plate (3-mm thickness, 16-mm width, and 2-mm internal dynamization per level). All the procedures were conducted with intraoperative neuromonitoring, including somatosensory

\section{TABLE 2. Summary of FOSS scores}

\begin{tabular}{cc}
\hline Score & Symptoms \\
\hline 0 & Normal function; asymptomatic \\
\hline 1 & Normal function; episodic or daily symptoms of dysphagia \\
\hline 2 & $\begin{array}{c}\text { Compensated abnormal function manifested by significant } \\
\text { dietary modifications or prolonged mealtimes (w/o } \\
\text { weight loss or aspiration) }\end{array}$ \\
\hline 3 & $\begin{array}{c}\text { Decompensated abnormal function; daily coughing, gag- } \\
\text { ging, or aspiration during meals }\end{array}$ \\
\hline 4 & $\begin{array}{c}\text { Severely decompensated abnormal function; severe } \\
\text { aspiration \& bronchopulmonary complications; nonoral } \\
\text { feeding for most nutrition }\end{array}$ \\
\hline 5 & Nonoral feeding for all nutrition \\
\hline
\end{tabular}




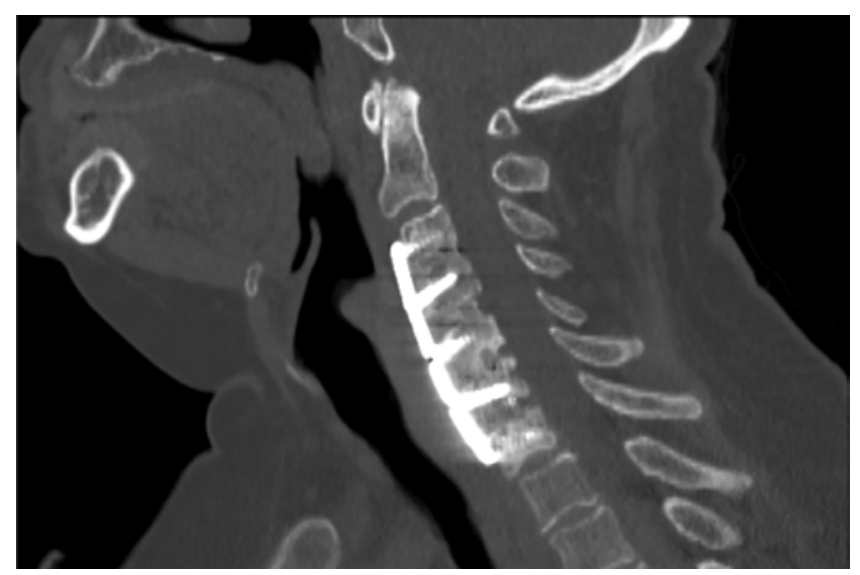

FIG. 1. CT scan showing fusion across all 4 levels 1 year after surgery. Note evidence of bridging bone and solid fusion across all levels, thus qualifying the spine as "fused" in the analysis.

evoked potentials, motor evoked potentials, and upperextremity electromyography. Postoperatively, each patient was treated with a hard cervical orthosis while upright or ambulatory for a duration of 4-6 weeks, after which time he or she was weaned from the cervical collar.

\section{Statistical Analysis}

Quantitative data are expressed in terms of mean values with corresponding standard deviations. The independent 2 -sample t-test was used for comparisons of variables; statistical significance was defined as a $p$ value of $<0.05$.

\section{Results}

At the conclusion of the study, 112 patients were enrolled; 56 received dexamethasone, and 56 received saline. Forty patients received 3-level fusions, 42 received 4-level fusions, 2 received 5-level fusions, and the remaining 28 received 2-level fusions. One of the patients in the steroid group required an additional course of postoperative outpatient steroids for continued difficulties with swallowing discovered during his follow-up visit. Of the placebo group, 8 patients required steroids postoperatively, 5 for severe dysphagia and 3 for airway concerns; 3 of these 8 patients required intubation in the perioperative course. One of these patients suffered a tonsillar laceration from intubation that required steroids to manage swelling and a formal ear, nose, and throat evaluation for prolonged swallowing dysfunction. One patient in the placebo group received 1 fewer dose because of a nursing error and was included in the final analysis. Analyses were repeated after the data for these patients were removed from the analysis to adjust for the effects of postoperative steroids.

Baseline demographic differences were insignificant between the 2 groups and are outlined in Table 3. Postoperative and follow-up information is also provided in Tables 4-7, which detail pain scores, myelopathy scores, swallowing function, and fusion rates and show no significant difference except for left upper-extremity pain at 3 months. Postoperative data collection began 1 month after surgery, at which time swallowing function was as-
TABLE 3. Comparison of demographic and baseline data*

\begin{tabular}{lccc}
\hline & \multicolumn{2}{c}{ Group } & \\
\cline { 2 - 3 } Parameter & Placebo & Dexa & p Value \\
\hline Sex $(\%$ male $)$ & 48.22 & 58.93 & 0.26 \\
\hline Age $(\mathrm{yrs})$ & 55 & 54 & 0.671 \\
\hline$\%$ smokers & 36.70 & 30.36 & 0.553 \\
\hline BMI $\left(\mathrm{kg} / \mathrm{m}^{2}\right)$ & 30.24 & 30.40 & 0.89 \\
\hline mJOA score & 0.13 & 13.75 & 0.287 \\
\hline FOSS score & 0.13 & 0.14 & 0.784 \\
\hline ODI score & 44.04 & 42.75 & 0.805 \\
\hline SF-12 PCS score & 31.65 & 33.91 & 0.215 \\
\hline SF-12 MCS score & 44.94 & 42.28 & 0.118 \\
\hline VAS score & & & \\
\hline Axial pain & 48.60 & 43.56 & 0.37 \\
\hline Right-arm pain & 32.70 & 32.70 & 0.99 \\
\hline Left-arm pain & 36.40 & 37.44 & 0.95 \\
\hline
\end{tabular}

$\mathrm{BMI}=$ body mass index; Dexa = dexamethasone; $\mathrm{MCS}=$ mental component summary; $\mathrm{mJOA}=$ modified Japanese Orthopaedic Association (scoring for myelopathy); PCS = physical component summary.

* Values are expressed as means unless noted otherwise.

sessed along with the incision, and more detailed followup was performed at $3,6,12$, and 24 months. Perioperative swallowing function, as detailed by FOSS score, patientreported dysphagia, length of stay, and airway difficulty, proved significantly worse in the placebo group than in the dexamethasone-treated group. When data for the patients who received steroids outside the protocol were removed from analysis, significance was maintained in terms of length of stay and postoperative FOSS score, patient-reported dysphagia, and airway difficulty.

Data were also analyzed at follow-up intervals $(6,12$, and 24 months) to assess pain, function, swallowing function, and fusion rates. It should be noted that there were no significant differences in the myelopathy scores, axial pain scores, extremity pain scores, Oswestry Disability Index (ODI) scores, or SF-12 scores (either mental summary component or physical summary component) at these in-

TABLE 4. Comparison of 3-month outcomes*

\begin{tabular}{lccc}
\hline & \multicolumn{2}{c}{ Group } & \\
\cline { 2 - 3 } Outcome & Placebo & Dexa & p Value \\
\hline mJOA score & 15.66 & 16.23 & 0.315 \\
\hline FOSS score & 0.261 & 0.14 & 0.445 \\
\hline ODI score & 34.82 & 31.38 & 0.763 \\
\hline SF-12 PCS score & 35.27 & 37.88 & 0.219 \\
\hline SF-12 MCS score & 46.93 & 46.62 & 0.656 \\
\hline VAS score & & & \\
\hline Axial pain & 29.3 & 26 & 0.85 \\
\hline Right-arm pain & 22.8 & 18.34 & 0.84 \\
\hline$\quad$ Left-arm pain & 22.8 & 15.43 & $0.04 \dagger$ \\
\hline * Values are expressed as means. & & \\
$\dagger$ Statistically significant. & &
\end{tabular}


TABLE 5. Comparison of 6-month outcomes*

\begin{tabular}{|c|c|c|c|}
\hline \multirow[b]{2}{*}{ Outcome } & \multicolumn{2}{|c|}{ Group } & \multirow[b]{2}{*}{$p$ Value } \\
\hline & Placebo & Dexa & \\
\hline mJOA score & 15.47 & 15.93 & 0.407 \\
\hline FOSS score & 0.174 & 0.2 & 0.768 \\
\hline ODI score & 36.42 & 32.75 & 0.796 \\
\hline SF-12 PCS score & 35.23 & 39.04 & 0.156 \\
\hline SF-12 MCS score & 45.13 & 45.98 & 0.888 \\
\hline \multicolumn{4}{|l|}{ VAS score } \\
\hline Axial pain & 28.2 & 27.01 & 0.84 \\
\hline Right-arm pain & 20.7 & 21.88 & 0.46 \\
\hline Left-arm pain & 22.3 & 17.43 & 0.91 \\
\hline Fusion rate (\%) & 60 & 39.50 & $0.0477 \dagger$ \\
\hline
\end{tabular}

tervals. The patients who received steroids had significantly lower fusion rates at 6 months, although by 12 months there was no difference in these rates. In the placebo group, 47 of 56 patients were followed up at 3 months, 49 of 56 at 6 months, and 41 of 56 at 12 months. In the steroid group, 46 of 56 patients were followed up at 3 months, 41 of 56 at 6 months, and 35 of 56 at 12 months. For those patients who did not attend follow-up, several of them had outpatient CT images sent to us for evaluation without a formal office visit. Other patients who underwent CT imaging for unrelated issues, typically for trauma or evaluation of neck pain in the emergency department, had their images evaluated for fusion status. Those who did not attend follow-up but who were noted in previous visits to have achieved fusion were assumed to have achieved fusion despite the lack of imaging. In the placebo group, the fusion rates at 6,12 , and 24 months were $60.0 \%, 80.0 \%$, and $95.2 \%$, respectively. FOSS scores in the steroid group were also evaluated, and although at the end of the study period there were no significant differences between the two groups, swallowing function was significantly worse in the placebo group at 1 month (0.66 vs 0.064; p = 0.027) (Fig. 2).

TABLE 6. Comparison of 12-month outcomes*

\begin{tabular}{lccc}
\hline & \multicolumn{2}{c}{ Group } & \\
\cline { 2 - 3 } Outcome & Placebo & Dexa & p Value \\
\hline mJOA score & 15.74 & 15.92 & 0.86 \\
\hline FOSS score & 0.1 & 0.26 & 0.375 \\
\hline ODI score & 33.12 & 31.76 & 0.913 \\
\hline SF-12 PCS score & 34.98 & 38.003 & 0.384 \\
\hline SF-12 MCS score & 47.22 & 46.78 & 0.662 \\
\hline VAS score & & & \\
\hline Axial pain & 25.6 & 31.62 & 0.37 \\
\hline Right-arm pain & 21.8 & 19.32 & 0.4 \\
\hline Left-arm pain & 21.4 & 28.09 & 0.19 \\
\hline Fusion rate (\%) & 80 & 75 & 0.57 \\
\hline
\end{tabular}

* Values are expressed as means unless noted otherwise.
TABLE 7. Comparison of 24-month outcomes*

\begin{tabular}{llll}
\hline & \multicolumn{2}{c}{ Group } & \\
\cline { 2 - 3 } Outcome & Placebo & Dexa & p Value \\
\hline mJOA score & 15.83 & 15.75 & 0.89 \\
\hline FOSS score & 0.0417 & 0.115 & 0.333 \\
\hline ODI score & 35.7 & 31.143 & 0.94 \\
\hline SF-12 PCS score & 34.6 & 35.84 & 0.672 \\
\hline SF-12 MCS score & 46.242 & 46.267 & 0.552 \\
\hline VAS score & & & \\
\hline Axial pain & 31.3 & 27.793 & 0.58 \\
\hline Right-arm pain & 20 & 26.41 & 0.4 \\
\hline Left-arm pain & 28 & 16.55 & 0.6 \\
\hline Fusion rate (\%) & 95.20 & 92.69 & 0.572 \\
\hline
\end{tabular}

* Values are expressed as means unless noted otherwise.

\section{Discussion}

In the surgical treatment of multilevel cervical pathology, potential complications of the anterior approach are often cited as the reason for selecting a posterior approach. With the extended retraction of the anterior neck structures necessitated by the anterior approach, both dysphagia and airway compromise become a significant concern. The severity and potential life-threatening nature of these complications from anterior cervical spinal surgery have prompted more thorough evaluations of their incidence and associated risk factors. $3,6,9,11,13,19,24,27-29,33$

The reported rates of dysphagia after anterior cervical surgery have varied widely, from $1 \%$ to $79 \% .^{9}$ In a prospective study, Lee et al. ${ }^{19}$ found the prevalence of postoperative dysphagia at $1,2,6,12$, and 24 months to be $54 \%$, $34 \%, 19 \%, 15 \%$, and $14 \%$, respectively. They concluded that postsurgical edema is probably the strongest contributor to dysphagia in the early postoperative period and that the amount of scar tissue plays a greater role than other factors in the long-term follow-up period. In addition, the more life-threatening complication of postoperative airway problems may occur in up to $6 \%$ of patients. ${ }^{4,9,11,29}$

Kepler et al. ${ }^{16}$ also found significantly increased dysphagia and soft-tissue shadowing on postoperative radiographs after 1- and 2-level ACDFs. The swelling decreased by 6 weeks but remained significant. They also noted that the degree of soft-tissue swelling did not correlate with postoperative dysphagia.

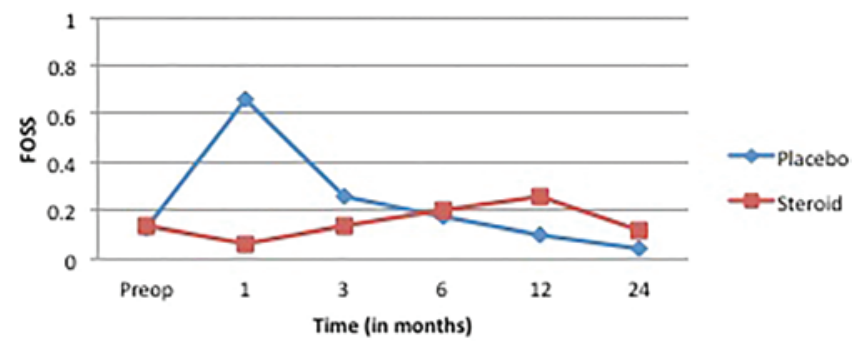

FIG. 2. Graph illustrating swallowing status after surgery in the placebo and steroid-treated groups. Figure is available in color online only. 
Another theoretical concern of steroid administration is infection. ACDF is known to result in significantly lower infection rates than posterior procedures, ${ }^{2,22}$ which is mirrored by the results of this study. There were no infections in either the steroid or the placebo group.

The role of steroids in the alleviation of edema in the structures of the anterior neck has been widely explored in the fields of otolaryngology, anesthesiology, and critical care medicine. . $^{1,12,15,18}$ The evaluation of perioperative steroid use in spinal surgery, however, has been relatively limited; only 1 study has provided Level 1 evidence. ${ }^{10,26,30}$ That study did not find a benefit for parenteral steroid use in expediting extubation after multilevel cervical corpectomy surgery. ${ }^{10}$ This paucity of data is largely a result of concern about deleterious effects on bone healing. Many investigators recommend that NSAIDs not be used in patients undergoing spinal fusion surgery. ${ }^{21}$ Although the data are generally conflicting, a large body of literature derived from laboratory studies suggests that NSAIDs either delay or inhibit bone healing. ${ }^{14}$ Regarding corticosteroids, 1 study in a rabbit model of posterior lumbar fusion showed that twice-daily injections over a 42-day period inhibited bone-graft incorporation. ${ }^{30}$

In 2011, Lee et al..$^{20}$ studied the effect of local steroids, given via triamcinolone and morcellized collagen sponge in the retropharyngeal space, in a prospective randomized study. They found significantly reduced prevertebral soft-tissue swelling in the upper cervical levels on lateral radiographs obtained immediately, 2 days, and 2 weeks after surgery. Furthermore, they found reduced severity of odynophagia 2 weeks after surgery in patients who were treated with local steroids.

In another study, ${ }^{23}$ dexamethasone administered intravenously was studied to evaluate for prevertebral swelling. Intravenous placebo or dexamethasone (40 or $80 \mathrm{mg}$ ) was administered, and the effects were examined by using daily radiographs for 5 days and patient-reported dyspnea and dysphagia VAS scores. Although their data indicated no significant difference in prevertebral swelling between the treated and untreated groups, Nam et al. ${ }^{23}$ noted that dexamethasone helped manage the severity of dyspnea during the initial postoperative days.

Our data are results of a prospective, randomized, double-blinded trial in which we analyzed the effects of perioperative steroid use in multilevel anterior cervical spine surgery. Between the 2 subgroups of patients, those who received steroids and those who were given an equivalent dose of placebo, there were no significant differences in any of the preoperative parameters, including baseline demographics, swallowing function, and pain and functional scale scores. Furthermore, postoperatively, with the exception of 3-month left upper-extremity pain, all outcome measures proved insignificant between the placebo and dexamethasone groups. This similarity helped to ensure that the results from the steroid and placebo groups can be compared reliably.

\section{Dysphagia}

In the perioperative and 1-month postoperative periods, we found significantly lower rates of dysphagia among patients in the steroid-treated group than in those in the pla- cebo group, which supports our hypothesis, as quantified by both the FOSS scores and the presence of any dysphagia as indicated by the patient. Also of note was that 7 of the patients in the placebo group required postoperative steroid treatment for severe dysphagia, whereas only 1 of the steroid-treated patients required continued steroids on follow-up, which also suggests the effectiveness of postoperative steroid use in controlling symptoms. This treatment consisted of dexamethasone given intravenously (10$\mathrm{mg}$ bolus followed by $4 \mathrm{mg}$ every 6 hours). This inference, however, may play into our inherent bias toward steroid treatment. Traditionally, our practice has noted that patients who undergo a multilevel ACDF typically remain in the hospital for concerns of dysphagia; from a pain standpoint, the operation is very well tolerated. It follows, therefore, that improved dysphagia in treated patients translated to shorter lengths of stay, which also proved significantly superior in the steroid-treated group. This result could be confounded by steroid euphoria.

\section{Airway Compromise}

The $2.7 \%$ rate of airway compromise in this study is similar to rates in previously published reports.,9,11,29 Three patients who had significant symptoms of respiratory difficulty required intubation; all of them had been randomly assigned to the placebo group and ultimately required intravenous dexamethasone for control of airway edema. Airway issues and need for intubation trended toward significance $(\mathrm{p}=0.057$ and 0.083 , respectively) and may prove significant with repeated studies in larger populations. No patient in the steroid group required intubation.

\section{Fusion}

Many spine surgeons acknowledge that corticosteroids have the potential to help limit some postoperative complications but are reluctant to use these medications routinely for fear that they may negatively impact bony fusion rates. Even in the setting of severe dysphagia or airwaydifficulty symptoms, there is still reluctance to use steroids for fear of these long-term effects. The results of our study show a significant difference between the placebo and steroid groups in fusion rates at 6 months $(60 \%$ vs $37.8 \%$, respectively; $\mathrm{p}=0.046$ ), although the differences in these rates at 12 and 24 months proved insignificant $(80 \%$ vs $75 \%$ [ $=0.53$ ] and $95.2 \%$ vs $92.7 \%$ [p $=0.57$, respectively). Thus, it seems that perioperative steroids delay the fusion process without affecting patient outcomes at any point, as indicated by both pain and functional outcome measures. When data from the patients who received additional steroids in the perioperative and immediate postoperative period were removed from analysis, fusion rates at 6 months approached but did not reach significance $(60.0 \%$ [placebo group] vs $39.5 \%$ [steroid group]; $p=0.064)$. This result may in part be a result of decreased power secondary to fewer subjects. At 12 and 24 months, fusion rates converged; the rates in the dexamethasone and placebo groups were $75 \%$ and $80 \%(\mathrm{p}=$ $0.577)$ at 12 months and $95.2 \%$ and $92.7 \%(\mathrm{p}=0.63)$ at 24 months, respectively (Fig. 3). 


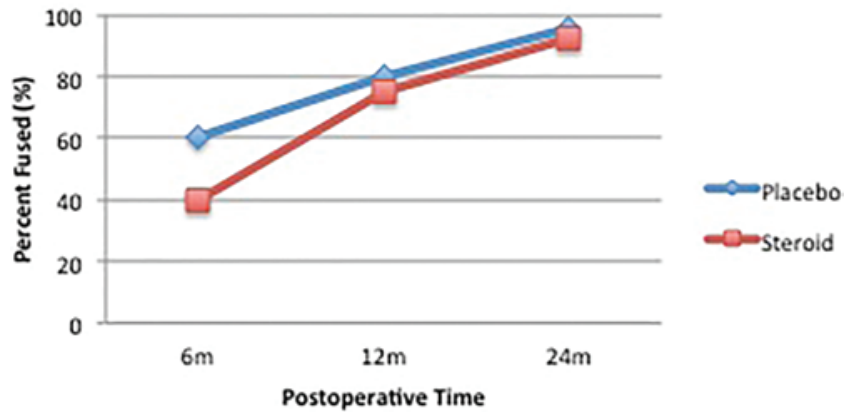

FIG. 3. Graph illustrating fusion rates 6,12 , and 24 months after surgery in the placebo and steroid-treated groups. Figure is available in color online only.

\section{Study Limitations/Future Directions}

The limitations of this study include the dexamethasone-dosing schedule used, which, although not standardized, is similar to that for other therapeutic indications and in previously published studies that examined multilevel cervical spine surgery. ${ }^{26}$ Another limitation is the use of the FOSS score to quantify dysphagia symptoms. This scale has been shown to be valid and reliable, but it is clinician based and not a comprehensive measure of quality of life. Also, although generated while the surgeon was blinded to the treatment groups, the fusion rates were jointly assessed by the senior surgeon (D.J.D.) and staff neuroradiologists, which could have inflated the fusion rates. Swallowing function was also assessed by the senior author. Additional limitations include the somewhatsignificant deviations from protocol; this study illustrated our inherent bias toward perhaps more liberal use of dexamethasone in the postoperative period for continued dysphagia. Because most significant cases of dysphagia occurred in the placebo group, and all of them were treated with steroid medication, the fusion rates could have been affected. However, despite removal of these data points from the analysis, fusion rates were still significantly different at 6 months but insignificant at 12 months. Last, the initial goal of the study was to obtain 200 patients with 2 years of follow-up data. However, there was significant difficulty in attaining acceptable follow-up rates at the 2-year mark. Furthermore, institutional approval for the study was terminated early secondary to significant results at the midterm analysis.

Future studies could include larger sample sizes to elucidate the role of steroids in potentially reducing airway compromise and the need for intubation. Furthermore, future studies could also determine the significance of fusion on clinical outcome. The role of fusion status in the development of adjacent-level disease could also be studied further. Additionally, improved methods for follow-up to 2 years should be implemented as well to evaluate both fusion and functional/pain-related outcomes. Low followup rates may also be partially secondary to patients seeking care elsewhere during the study period.

Last, although there was no difference between levels fused in both cohorts, future studies can more evenly match the number of levels fused to assist in standardizing the data.

\section{Conclusions}

Our results suggest that the use of perioperative steroids in multilevel anterior cervical surgery helps limit symptoms of both dysphagia and airway compromise. Although it delayed fusion in the short term, perioperative steroid use did not negatively affect long-term fusion rates.

\section{References}

1. Bagshaw SM, Delaney A, Farrell C, Drummond J, Brindley PG: Best evidence in critical care medicine. Steroids to prevent post-extubation airway obstruction in adult critically ill patients. Can J Anaesth 55:382-385, 2008

2. Barnes M, Liew S: The incidence of infection after posterior cervical spine surgery: a 10 year review. Global Spine J 2:3-6, 2012

3. Bazaz R, Lee MJ, Yoo JU: Incidence of dysphagia after anterior cervical spine surgery: a prospective study. Spine (Phila Pa 1976) 27:2453-2458, 2002

4. Boakye M, Patil CG, Ho C, Lad SP: Cervical corpectomy: complications and outcomes. Neurosurgery 63 (4 Suppl 2):295-302, 2008

5. Cabraja M, Abbushi A, Koeppen D, Kroppenstedt S, Woiciechowsky C: Comparison between anterior and posterior decompression with instrumentation for cervical spondylotic myelopathy: sagittal alignment and clinical outcome. Neurosurg Focus 28(3):E15, 2010

6. Campbell PG, Yadla S, Malone J, Zussman B, Maltenfort $\mathrm{MG}$, Sharan AD, et al: Early complications related to approach in cervical spine surgery: single-center prospective study. World Neurosurg 74:363-368, 2010

7. Chiu AG, Newkirk KA, Davidson BJ, Burningham AR, Krowiak EJ, Deeb ZE: Angiotensin-converting enzyme inhibitor-induced angioedema: a multicenter review and an algorithm for airway management. Ann Otol Rhinol Laryngol 110:834-840, 2001

8. Cloward RB: The anterior approach for removal of ruptured cervical disks. J Neurosurg 15:602-617, 1958

9. Daniels AH, Riew KD, Yoo JU, Ching A, Birchard KR, Kranenburg AJ, et al: Adverse events associated with anterior cervical spine surgery. J Am Acad Orthop Surg 16:729738, 2008

10. Emery SE, Akhavan S, Miller P, Furey CG, Yoo JU, Rowbottom JR, et al: Steroids and risk factors for airway compromise in multilevel cervical corpectomy patients: a prospective, randomized, double-blind study. Spine (Phila Pa 1976) 34:229-232, 2009

11. Epstein NE, Hollingsworth R, Nardi D, Singer J: Can airway complications following multilevel anterior cervical surgery be avoided? J Neurosurg 94 (2 Suppl):185-188, 2001

12. Fan T, Wang G, Mao B, Xiong B, Zhang U, Liu X, et al: Prophylactic administration of parenteral steroids for preventing airway complications after extubation in adults: meta-analysis of randomised placebo controlled trials. BMJ 337:a1841, 2008

13. Fountas KN, Kapsalaki EZ, Nikolakakos LG, Smisson HF, Johnston KW, Grigorian AA, et al: Anterior cervical discectomy and fusion associated complications. Spine (Phila Pa 1976) 32:2310-2317, 2007

14. Ho ML, Chang JK, Wang GJ: Antiinflammatory drug effects on bone repair and remodeling in rabbits. Clin Orthop Relat Res (313):270-278, 1995

15. Hughes R, McGuire G, Montanera W, Wong D, Carmichael FJ: Upper airway edema after carotid endarterectomy: the effect of steroid administration. Anesth Analg 84:475-478, 1997

16. Kepler CK, Rihn JA, Bennett JD, Anderson DG, Vaccaro AR, Albert TJ, et al: Dysphagia and soft-tissue swelling after 
anterior cervical surgery: a radiographic analysis. Spine J 12:639-644, 2012

17. Korinth MC: Treatment of cervical degenerative disc disease - current status and trends. Zentralbl Neurochir 69:113124, 2008

18. Lee CH, Peng MJ, Wu CL: Dexamethasone to prevent postextubation airway obstruction in adults: a prospective, randomized, double-blind, placebo-controlled study. Crit Care 11:R72, 2007

19. Lee MJ, Bazaz R, Furey CG, Yoo J: Risk factors for dysphagia after anterior cervical spine surgery: a two-year prospective cohort study. Spine J 7:141-147, 2007

20. Lee SH, Kim KT, Suk KS, Park KJ, Oh KI: Effect of retropharyngeal steroid on prevertebral soft tissue swelling following anterior cervical discectomy and fusion: a prospective, randomized study. Spine (Phila Pa 1976) 36:22862292, 2011

21. Maxy RJ, Glassman SD: The effect of nonsteroidal antiinflammatory drugs on osteogenesis and spinal fusion. Reg Anesth Pain Med 26:156-158, 2001

22. Miller LE, Block JE: Safety and effectiveness of bone allografts in anterior cervical discectomy and fusion surgery. Spine (Phila Pa 1976) 36:2045-2050, 2011

23. Nam TW, Lee DH, Shin JK, Goh TS, Lee JS: Effect of intravenous dexamethasone on prevertebral soft tissue swelling after anterior cervical discectomy and fusion. Acta Orthop Belg 79:211-215, 2013

24. Ozgursoy OB, Salassa JR, Reimer R, Wharen RE, Deen HG: Anterior cervical osteophyte dysphagia: manofluorographic and functional outcomes after surgery. Head Neck 32:588593, 2010

25. Patil PG, Turner DA, Pietrobon R: National trends in surgical procedures for degenerative cervical spine disease: 1990 2000. Neurosurgery 57:753-758, 2005

26. Pedram M, Castagnera L, Carat X, Macouillard G, Vital JM: Pharyngolaryngeal lesions in patients undergoing cervical spine surgery through the anterior approach: contribution of methylprednisolone. Eur Spine J 12:84-90, 2003

27. Rihn JA, Kane J, Albert TJ, Vaccaro AR, Hilibrand AS: What is the incidence and severity of dysphagia after anterior cervical surgery? Clin Orthop Relat Res 469:658-665, 2011

28. Riley LH III, Vaccaro AR, Dettori JR, Hashimoto R: Postoperative dysphagia in anterior cervical spine surgery. Spine (Phila Pa 1976) 35 (9 Suppl):S76-S85, 2010

29. Sagi HC, Beutler W, Carroll E, Connolly PJ: Airway complications associated with surgery on the anterior cervical spine. Spine (Phila Pa 1976) 27:949-953, 2002
30. Sawin PD, Dickman CA, Crawford NR, Melton MS, Bichard WD, Sonntag VK: The effects of dexamethasone on bone fusion in an experimental model of posterolateral lumbar spinal arthrodesis. J Neurosurg 94 (1 Suppl):76-81, 2001

31. Shamji MF, Cook C, Pietrobon R, Tackett S, Brown C, Isaacs RE: Impact of surgical approach on complications and resource utilization of cervical spine fusion: a nationwide perspective to the surgical treatment of diffuse cervical spondylosis. Spine J 9:31-38, 2009

32. Smith GW, Robinson RA: The treatment of certain cervicalspine disorders by anterior removal of the intervertebral disc and interbody fusion. J Bone Joint Surg Am 40-A:607-624, 1958

33. Smith-Hammond CA, New KC, Pietrobon R, Curtis DJ, Scharver CH, Turner DA: Prospective analysis of incidence and risk factors of dysphagia in spine surgery patients: comparison of anterior cervical, posterior cervical, and lumbar procedures. Spine (Phila Pa 1976) 29:1441-1446, 2004

34. Song KJ, Lee SK, Ko JH, Yoo MJ, Kim DY, Lee KB: The clinical efficacy of short-term steroid treatment in multilevel anterior cervical arthrodesis. Spine J 14:2954-2958, 2014

\section{Author Contributions}

Conception and design: Petronis, Drazin, DiRisio. Acquisition of data: Jeyamohan, Kenning, Petronis, DiRisio. Analysis and interpretation of data: Jeyamohan, Kenning, Feustel, DiRisio. Drafting the article: Jeyamohan, Kenning, DiRisio. Critically revising the article: Jeyamohan, DiRisio. Reviewed submitted version of manuscript: Jeyamohan, DiRisio. Approved the final version of the manuscript on behalf of all authors: Jeyamohan. Statistical analysis: Jeyamohan, Kenning, DiRisio, Feustel. Administrative/ technical/material support: Petronis, DiRisio. Study supervision: Petronis, DiRisio.

\section{Supplemental Information \\ Current Affiliation}

Dr. Drazin: Department of Neurosurgery, Spine Center, CedarsSinai Medical Center, Los Angeles, CA.

\section{Correspondence}

Shiveindra B. Jeyamohan, 47 New Scotland Ave., MC-10, Albany, NY 12208. email: jeyamos@mail.amc.edu. 